\title{
MBLR, a new RING finger protein resembling mammalian Polycomb gene products, is regulated by cell cycle-dependent phosphorylation
}

\author{
Takeshi Akasaka ${ }^{1,3, *}$, Naomi Takahashi ${ }^{2}$, Maki Suzuki ${ }^{3}$, Haruhiko Koseki ${ }^{3}$, Rolf Bodmer ${ }^{1}$ and \\ Hisashi Koga ${ }^{2, a, *}$ \\ ${ }^{1}$ Department of Cellular, Molecular and Developmental Biology, University of Michigan, 830 N University, Ann Arbor, MI, 48109-1048, USA \\ ${ }^{2}$ Helix Research Institute, 1532-3 Yana, Kisarazu-city, Chiba, 292-0812, Japan \\ ${ }^{3}$ Department of Molecular Embryology, Graduate School of Medicine, Chiba University, 1-8-1 Inohana, Chuou-ku, Chiba-city, Chiba, \\ 260-8670, Japan
}

\begin{abstract}
Background: The RING finger proteins function in a variety of fundamental cellular processes. The products of some members of the Polycomb group $(\mathrm{PcG})$ bear ring finger domains and are defined as a subclass of RING finger proteins. Among them are Drosophila posterior sex combs and suppressor 2 of zeste, whose RING fingers are conserved in vertebrate PcG proteins Mel18 and Bmi1.

Results: We have identified a new mammalian RING finger protein, termed MBLR due to its structural similarity to Mel18 and Bmi1 (Mel18 and Bmi1-like RING finger protein). MBLR interacts with some PcG proteins: in vitro biochemical data support the idea of a direct interaction of MBLR's RING finger domain with Ring1B, which is highly homologous to one of the mammalian PcG genes, Ring1A. We also show that MBLR acts as a transcriptional
\end{abstract}

\section{Introduction}

The RING finger motif is characterized by a cysteinerich $\mathrm{Zn}^{2+}$-binding domain and defines a superfamily of diverse proteins (Borden \& Freemont 1996; Freemont 1993). The RING finger domains are involved in proteinDNA and protein-protein interactions and E2-dependent ubiquitinations and, consequently, function in a variety of fundamental cellular processes including the

Communicated by: Shinichi Aizawa

*Correspondence: takasaka@umich.edu and hkoga@kazusa.or.jp a Present address: Kazusa DNA Research Institute, 1532-3 Yana, Kisarazu-city, Chiba 292-0812, Japan. repressor in transiently transfected cells, as is the case for other PcG proteins. Immunocytochemical analysis reveals that MBLR protein is localized in a fine-grained distribution throughout the nucleoplasm in interphase cultured cells and in a fainter diffuse cytoplasmic distribution in mitotic cells. In addition, we find that serine 32 of MBLR is specifically phosphorylated during mitosis, most likely by CDK7, a component of the basal transcriptional machinery.

Conclusion: Similarities to previously defined PcG proteins suggest that MBLR should be included in the same subclass of RING finger proteins as Mel18 and Bmi1. Although the biological relevance of the cell cycle-related phosphorylation remains to be demonstrated, serine 32 phosphorylation could nevertheless be functionally important. regulation of gene expression, signal transduction and proteolysis (Freemont 2000; Jackson et al. 2000; Joazeiro \& Weissman 2000). Although cysteine-cysteine/histidine pairs are conserved among RING finger proteins, amino acid sequences between these cysteine-cysteine/ histidine pairs and at the linking region between the two finger-like domains have diverged, thereby providing a molecular basis for the functional heterogeneity of the RING finger domains.

Functional insights into the RING finger domains are in part obtained from genetic and molecular analyses of Drosophila and mammalian Polycomb group (PcG) gene products. The Drosophila PcG proteins posterior sex combs (Psc), and its neighbouring and related gene 
product, the suppressor two of zeste [Su(z)2], share sequence homology with the mammalian $\mathrm{PcG}$ proteins, Mel18 and Bmi1 in their RING finger domains. This homology defines a subclass of RING finger proteins which are conserved between invertebrates and vertebrates (Brunk et al. 1991; Ishida et al. 1993; Tagawa et al. 1990; van Lohuizen et al. 1991). Interestingly, all of the RING finger proteins listed above contain the helixturn-helix (HTH) domain.

The $P c G$ genes were first identified in Drosophila as a group of genes required for the maintenance of stable repression of Hox cluster genes during development (Bienz \& Muller 1995; Kennison 1995; Paro 1995; Pirrotta 1997b, 1998; Simon 1995). Biochemical and immunohistochemical analyses indicate that Drosophila PcG gene products function as large multimeric protein complexes which are thought to act by changing the local chromatin structure (Orlando \& Paro 1995; Paro 1995; Pirrotta 1997b). Synergistically genetic interactions between mutant alleles of different Drosophila PcG genes indicate their capability to affect the expression of Hox genes in a gene dosage-dependent manner and this is in accordance with the action of PcG gene products in multimeric protein complex (Franke et al. 1992; Shao et al. 1999).

Psc and $S u(z) 2$ encode large proteins exhibiting a sequence similarity in their RING finger and HTH domains. $S u(z) 2$, although not strictly a PcG protein, functions as a modifier of zeste loci like Psc, enhancer of zeste $[\mathrm{E}(\mathrm{z})]$ and sex comb on midleg $(\mathrm{Scm})$ and seems to interact genetically with $P s c$ and $S c m$ mutations (Platero et al. 1996; Wallrath \& Elgin 1995; Wu \& Howe 1995). The Psc and $\mathrm{Su}(\mathrm{z}) 2$ products have been shown to colocalize on more than 80 sites in salivary gland polytene chromosomes, and their association with chromosomes is dependent on the active $\mathrm{E}(\mathrm{z})$ protein (DeCamillis et al. 1992; Franke et al. 1995; Rastelli et al. 1993; Zink \& Paro 1989). The RING finger domain of the Psc protein is involved in the interaction with polycomb $(\mathrm{Pc})$ protein, which is thought to be essential for its repression of gene expression (Kyba \& Brock 1998). The Drosophila lethal(3)73Ah gene has been shown to encode a RING finger protein homologous to the Psc and $\mathrm{Su}(\mathrm{z}) 2$ proteins, but its specific function has not yet been determined (Irminger-Finger \& Nothiger 1995).

An increasing number of mammalian genes structurally and functionally related to Drosophila PcG proteins are being identified. Mammalian Bmi1 and Mel18 share highly homologous domains with $\mathrm{Psc}$ and $\mathrm{Su}(\mathrm{z}) 2$ but are much smaller in weight (Tagawa et al. 1990; van Lohuizen et al. 1991). Mice bearing null mutations in either of these genes show rather subtle posterior transformations of their axial skeletons (Akasaka et al. 1996; van der Lugt et al. 1994), accompanied by extended domains of Hox gene expression in the paraxial mesoderm to the neighbouring, anterior prevertebra (Akasaka et al. 1997; van der Lugt et al. 1994, 1996). Recently, we have shown that Mel18/Bmi1 double mutant mice exhibit a strong synergistic effect in their ectopic expression of Hox cluster genes (Akasaka et al. 2001). For example, Hoxb3, Hoxb6 and Hoxc6 expression domains are all shifted up to the forebrain at day 9.5, whereas the Hoxd 4 expression domain is less affected in these mutant mice. One possible explanation for the different extent among the Hox gene de-repression is the existence of another Psc resembling gene product, which has a function redundant with Mel18/Bmi1. Quite recently, NSPc1 was isolated, a gene sharing sequence similarity to Mel18 and Bmi1 (Nunes et al. 2001). However, it is not clear whether NSPC1 plays a compensatory role in Hox gene de-repression.

Moreover, it has been shown that Bmi1 and Mel18 regulate cell proliferation and senescence via repression of the Ink4a/Avf locus (Jacobs et al.1999a,b). It has also been reported that chromatin association of Bmi1 inversely correlates with its phosphorylation status in a cell cycle-dependent fashion (Voncken et al. 1999). This is the first report on the modification and cell cycledependent regulation of a $\mathrm{PcG}$ protein. Elucidation of the mechanism of $\mathrm{PcG}$ modifications should provide a better understanding of how and when PcG proteins form large protein complexes at specific genomic targets.

In this study, we have attempted to identify another Mel18/Bmi1 related gene based on structural similarities to their RING finger domains and identified human and mouse MBLRs (Mel18- and Bmi1-like RING finger proteins). Our experiments demonstrate the physical association of MBLR with Ring1A, Ring1B and Bmi1, transcriptional repression, and the subcellular localization of the MBLR protein. These observations suggest that the functions of MBLR protein are similar to those of Mel18 and Bmil. We also show that the phosphorylation of MBLR occurs during mitosis and that CDK7, a component of basal transcriptional machinery (Bregman et al. 2000; Kaldis 1999; Nigg 1996), can phosphorylate MBLR. Furthermore, we identified the phosphorylation site of MBLR as serine 32. The implications of our observations are that MBLR is included in same subclass of RING finger proteins such as Mel18 and Bmi1 and that phosphorylation is a key modification step for the cell cycle-dependent regulation of MBLR. 


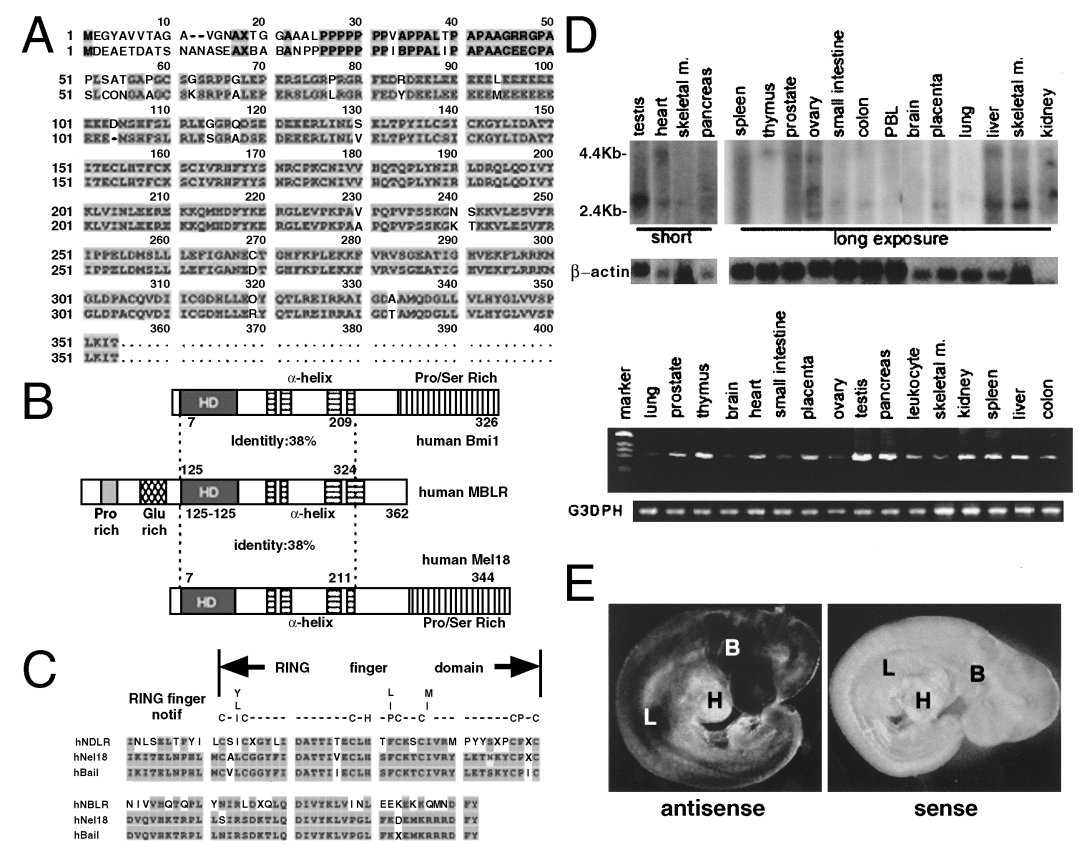

Figure 1 Amino acid sequences of human and mouse MBLR and expression profile of MBLR transcripts. (A) Alignment of deduced amino acid sequences encoded by the human (upper row) and mouse (lower row) MBLR cDNAs. Sequences were aligned using the Multiple Sequence Alignments at the BCM Search Launcher <http://dot.imgen.bcm.tmc.edu:9331/multialign/multialign.html>. The residues that are conserved between human and mouse are indicated by shading. (B) Schematic representation of MBLR, Mel18 and Bmi1 proteins. Black boxes represent the highly homologous domains (HD): striped boxes represent conserved $\alpha$-helix and proline serine rich motifs. (C) Alignment of the highly homologous domains (HD) of the hMBLR, hMel18 and hBmi1 proteins. Amino acid residues identical in the same position are indicated by shading. Consensus sequences of the RING finger domain are written on the top of the alignment. (D) Expression of $h M B L R$ transcripts in various human adult tissues. Upper panel; Northern blot analysis. Each lane contains $2 \mu \mathrm{g}$ of $\operatorname{poly}(\mathrm{A})+\mathrm{RNA}$. The blots were hybridized with a cDNA probe specific for $h M B L R$ and $\beta$-actin. The names of the tissues are written on the top of the panels. The $2.5 \mathrm{~kb} h M B L R$ transcript is indicated by an arrowhead. The short (left) and long (right) exposures show that MBLR is expressed ubiquitously in all tissues. For $\beta$-actin the exposure time is same for all tissues. Lower panel; RT-PCR analysis. $h M B L R$ transcripts were amplified from a Multiple Tissue cDNA Panel (Clontech) with a set of $h M B L R$ specific primers and control G3PDH-specific primers. (E) In situ hybridization analysis of $m M B L R$ transcripts. Lateral views of whole mount preparations of $10.5 \mathrm{dpc}$ mouse embryos hybridized with anti-sense (left) and sense (right) riboprobes. $m M B L R$ signal is detected in most embryonic tissues, especially in the bronchial arches (B) and the limb buds (L), with the main exception of the heart $(\mathrm{H})$.

\section{Results}

\section{Isolation of cDNAs coding for proteins that have high sequence homology with the RING finger domain of Mel18 and Bmi1}

In an effort to structurally isolate genes encoding proteins with RING fingers related to those of Mel18 and Bmi1, we searched the Human Novel Transcripts (Hunt) Human Full Length cDNA Database <http:// helix-www.hri.co.jp:443/HRIDB/> using the BLAST algorithm (Yudate et al.2001).A BLAST search of the Hunt database using the peptide sequences of the RING finger domain of Mel18 and Bmi1 revealed a Helix clone with a high sequence similarity. However, translation of this cDNA clone was interrupted by an insertion. We designed several primers and obtained a cDNA, which contains a single large open reading frame (ORF) encoding a polypeptide of 352 amino acids (aa) (Fig. 1A). The predicted first methionine is defined by a good fit with the Kozak's consensus sequence A/ GXXATGG (the reliability of ATGPR program < http:// www.hri.co.jp/atgpr/> is 0.78). Because of its similarity to the RING finger domain of Mel18 and Bmi1, we

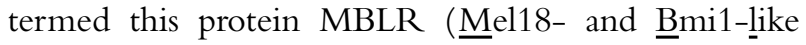
RING finger protein).

A comparison of the amino acid sequence of MBLR with Mel18 and Bmi1 revealed that MBLR consists of at least three distinct domains (Fig. 1B). Highly homologous domain (HD) to Mel18 and Bmi1 is located in the central region of MBLR protein (amino acids 125-216). 
The RING finger domain (amino acids 136-174) is seen in the N-terminal half of the HD exhibiting $62 \%$ and $64 \%$ identities to the analogous domain of Mel18 and Bmi1, respectively (Fig. 1C). The C-terminal half of the HD also shows extensive similarity to not only Mel18 and Bmi1 but also Drosophila Psc and $\mathrm{Su}(\mathrm{z}) 2$.The overall identities of the HD are 58\% (Mel18), 55\% (Bmi1), 49\% (Psc) and 36\% [Su(z)2]. A HTH domain is predicted in the C-terminal region (amino acids 240-324) of MBLR by using the method of Chou \& Fasman (1978), which is also characteristic of Mel18 and Bmi1, while the amino acid sequence is rather diverged. However, amino acid identities in this region are 31\% (Mel18) and 28\% (Bmi1) and the amino acid similarities are 54\% (Mel18) and $49 \%$ (Bmi1). Thus, the tertiary structure of MBLR in this domain could be similar to the analogous domain of Mel18 and Bmi1. The N-terminal region (amino acids 1-101) containing proline- and glutamic acid-rich domains is a unique structure for MBLR, while the C-terminal PEST region seen in Mel18 and Bmi1 is absent in MBLR. The amino acid sequence between the RING finger and HTH domains have a 38\% identity with that of Mel18 and Bmi1.The MOTIF search program (Goodmotif, Memsat and Psort) could not predict any known domain except for the RING finger.

Based on this sequence, we isolated the murine counterpart of $M B L R$ gene. In order to isolate mouse $M B L R$ (mMBLR), we performed a TBLASTN search of the GENBANK database using the human MBLR sequence and obtained overlapping expressed-sequence tag (EST) cDNA clones (AA414523, AA764577, AL034737, AA242737, AA920315, AI121824, AA153848, AA43956, AA139711, AA864091 and AA675640). We then performed 5' RACE on a mouse embryo cDNA library and finally obtained an $1828 \mathrm{bp}$ cDNA, which contains an ORF encoding a mouse MBLR (353 amino acids) (Fig. 1A). A comparison between the DNA sequences of the human and mouse MBLR cDNAs showed good conservation in the coding regions, which encode proteins with almost identical amino acid sequences (Fig. 1A, identity; 87\%).

\section{The expression of MBLR gene in adult and embryonic tissues}

To determine the expression pattern of the $h M B L R$ gene we analysed polyA mRNA transcripts from various adult human tissues by Northern blot analysis. High levels of a $2.5 \mathrm{~kb}$ human MBLR transcript were detected in testis and lower levels in heart (Fig. 1D, left upper panel). After a longer exposure of the membrane, the transcript was also detected in other tissues (Fig. 1D, right upper panel). RT-PCR analysis confirmed this ubiquitous expression pattern (Fig. 1D, Lower panel). A longer $h M B L R$ transcript (about $4.5 \mathrm{~kb}$ ) was also detected, although at lower levels than that of the predominant $2.5 \mathrm{~kb}$ transcript. Analysis of $m M B L R$ transcripts in the developing embryo by whole mount in situ hybridization of 10.5 days post-coitus (dpc) mouse embryo revealed almost ubiquitous expression. The strongest MBLR hybridization signals were detected in the facial mesenchyme, branchial arches and limb buds (Fig. 1E).

\section{Expression and subcellular localization of endogenous MBLR protein}

To examine the expression and subcellular localization of hMBLR, we obtained the polyclonal anti-hMBLR antibody, pABR 0 , raised against the recombinant hMBLR protein. To evaluate the specificity of this antibody, we performed a Western blot analysis of extracts from HEK293 cells transiently transfected with a MychMBLR construct and with extracts from U2OS osteosarcoma cells, which are known to express high levels of many PcG proteins. Using pAbR 0 , we detected bands in both cell extracts with mobilities corresponding to polypeptides of approximately 60 and $65 \mathrm{kDa}$. This coincides with the mobility of the transfected hMBLR detected with the anti-Myc antibody (Fig. 2A, left and right panels, respectively). Neither over-expressed nor endogenous hMBLR protein was detected with preimmune serum (Fig. 2A, central panel). The pABR0 antibody cross-reacts to the murine MBLR in a specific manner (data not shown). Therefore, this antibody appears to have the expected specificity for hMBLR and was used in subsequent experiments. The presence of additional bands in these blots may be an indication that the hMBLR protein may undergo post-translational modification.

Using the anti-hMBLR antibody, pAbR0, we confirmed the expression of endogenous MBLR in various adult tissues by Western blotting (Fig. 2B). Consistent with Northern blotting, the highest expression level was detected in testis, and lower levels are seen in ovary, heart, stomach, liver, thymus and kidney. However, there still remains the discrepancy of the expression level between adult and embryonic heart. One possibility is that the amount of MBLR protein might be controlled during developing stages.

We next analysed the subcellular localization of the endogenous MBLR protein in tissue culture cell lines (U2OS, L cells and CHP134 cells) and in primary cultures (Emfis). In all cases, we found that hMBLR is 


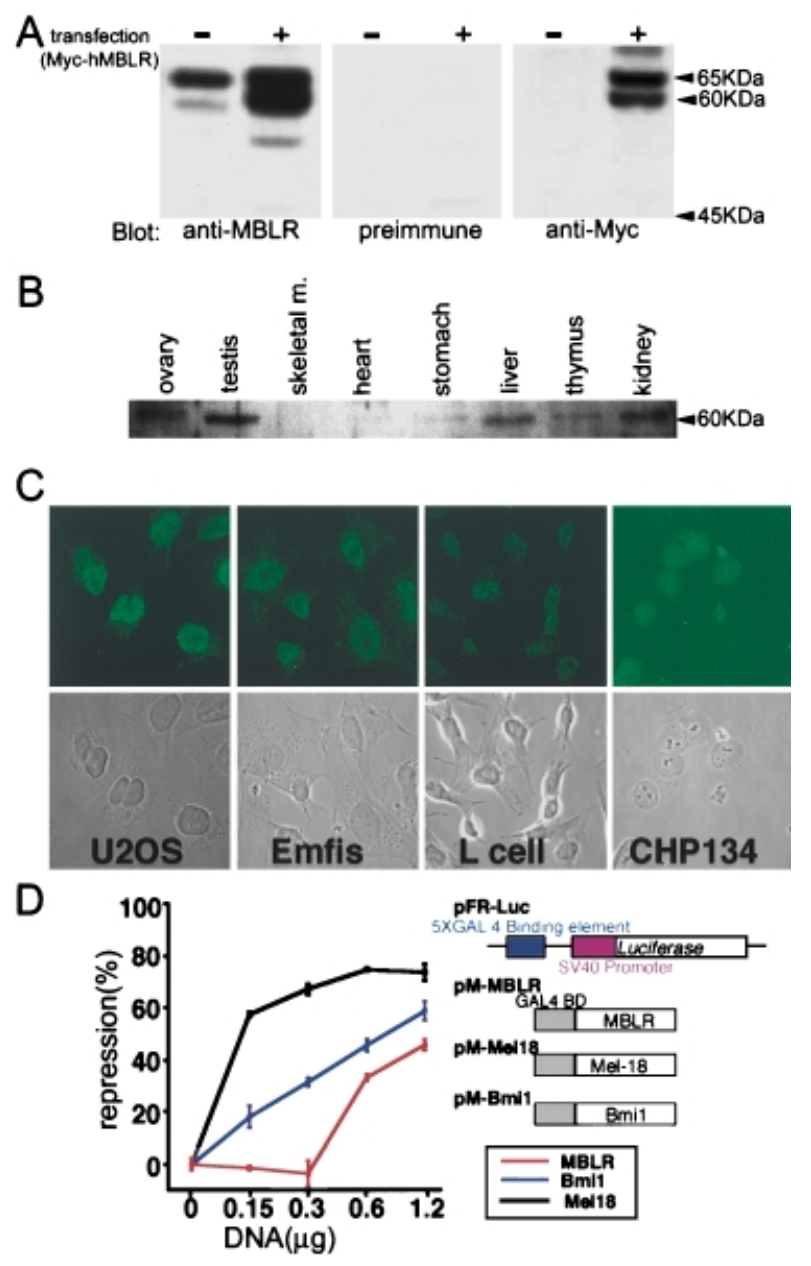

Figure 2 Western blot and immunocytocheminal analyses of endogenous MBLR, and transcriptional repression by MBLR in transiently transfected mammalian cells. (A) Lysates from HEK293 cells transfected with the Myc-tagged-MBLR expression plasmid (+) and U2OS cell (-) were resolved by $10 \%$ SDS-PAGE, and analysed by Western blot using anti-MBLR antibody, pre-immune serum, and anti-Myc antibody. (B) Western blot analysis of MBLR protein in various mouse adult tissues. Each lane contains $10 \mu \mathrm{g}$ of total protein. The $60 \mathrm{kDa}$ band of endogenous MBLR protein is indicated by an arrowhead. (C) Subcellular localization of endogenous MBLR. Four cell lines were stained with anti-MBLR antibody and analysed by confocal microscopy. Upper panels represent MBLR staining, lower panels represent phase contrast views. (D) L cells were serially co-transfected with increasing amounts of the pM-MBLR, pM-Mel18 or pM-Bmi1 plasmids $(0.15-1.2 \mu \mathrm{g})$ together with the reporter plasmid. Photinus pyralis Luciferase activities were determined $40 \mathrm{~h}$ after transfection and the results were normalized against Renilla luciferase activity. The average of repression values by GAL4DBD fusion proteins of three different experiments are shown along with the SD. A schematic representation of the reporter and the pM constructs is shown on the right. exclusively seen in the nucleus of the interphase cells, excluded from the nucleolus (Fig. 2C). The staining of these cell lines using pre-immune serum did not show any specific staining (data not shown).

\section{MBLR is a transcriptional repressor}

Mel18 and Bmi1, like all other PcG proteins, act as transcriptional repressors when tethered on the episomal reporter plasmid (Bunker \& Kingston 1994; Cohen et al. 1996; Schoorlemmer et al. 1997). The structural similarity of MBLR to Mel18 and Bmi1 prompted us to examine its transcriptional activity in transiently transfected mammalian cells. The coding sequences of $h M B L R$, Mel18 and Bmi1 were fused to the GAL4DBD of pM plasmid. The transcriptional activity of these fusion proteins were assessed on a reporter plasmid in which luciferase expression is driven by several GAL4-binding sites (Fig. 2D, right). Co-transfection of pM-hMBLR plasmid and the reporter plasmid into L cells resulted in up to a $50 \%$ repression of luciferase activity in a dose-dependent manner (Fig. 2D, left). A GAL4DBDhMBLR fusion protein did not show any significant repression on a reporter plasmid lacking GAL4-binding sites (data not shown). In the same assay, both GAL4DBD-Mel18 and GAL4DBD-Bmi1-fusion proteins showed a higher repressor activity than that of GAL4DBD-hMBLR (Fig. 2D, left). The same results were obtained in U2OS cells (data not shown).

\section{MBLR interacts with Ring1B via its highly homologous domain (HD)}

Because of the structural and functional resemblance of mammalian MBLR to Mel18 and Bmi1, we asked whether MBLR is part of the $\mathrm{PcG}$ complex. To address this, we investigated the interaction of hMBLR with a number of components of the PcG complex (Mel18, Bmi1, Ring1A, Ring1B and Mph2) using a yeast twohybrid assay. We found that hMBLR interacted strongly with Ring1A and Ring1B, moderately with Bmi1, and weakly with Mph2, but not at all with Mel18 or the negative control (lamin) (Fig. 3A, top panel). In addition, the screening of about $7 \times 10^{6}$ clones of a mouse $11 \mathrm{dpc}$ embryo cDNA library using LexA-hMBLR as bait resulted in half of the positive clones encoding Ring1B (the other hMBLR-interacting proteins identified in this screening will be described elsewhere). Because of this, we decided to study the interaction between hMBLR and Ring1B in more detail by using an in vitro GST pulldown assay. We showed that ${ }^{35} \mathrm{~S}-\mathrm{hMBLR}$ was bound to GST-Ring1B, and that ${ }^{35} \mathrm{~S}-\mathrm{R}$ ing $1 \mathrm{~B}$ interacted with 

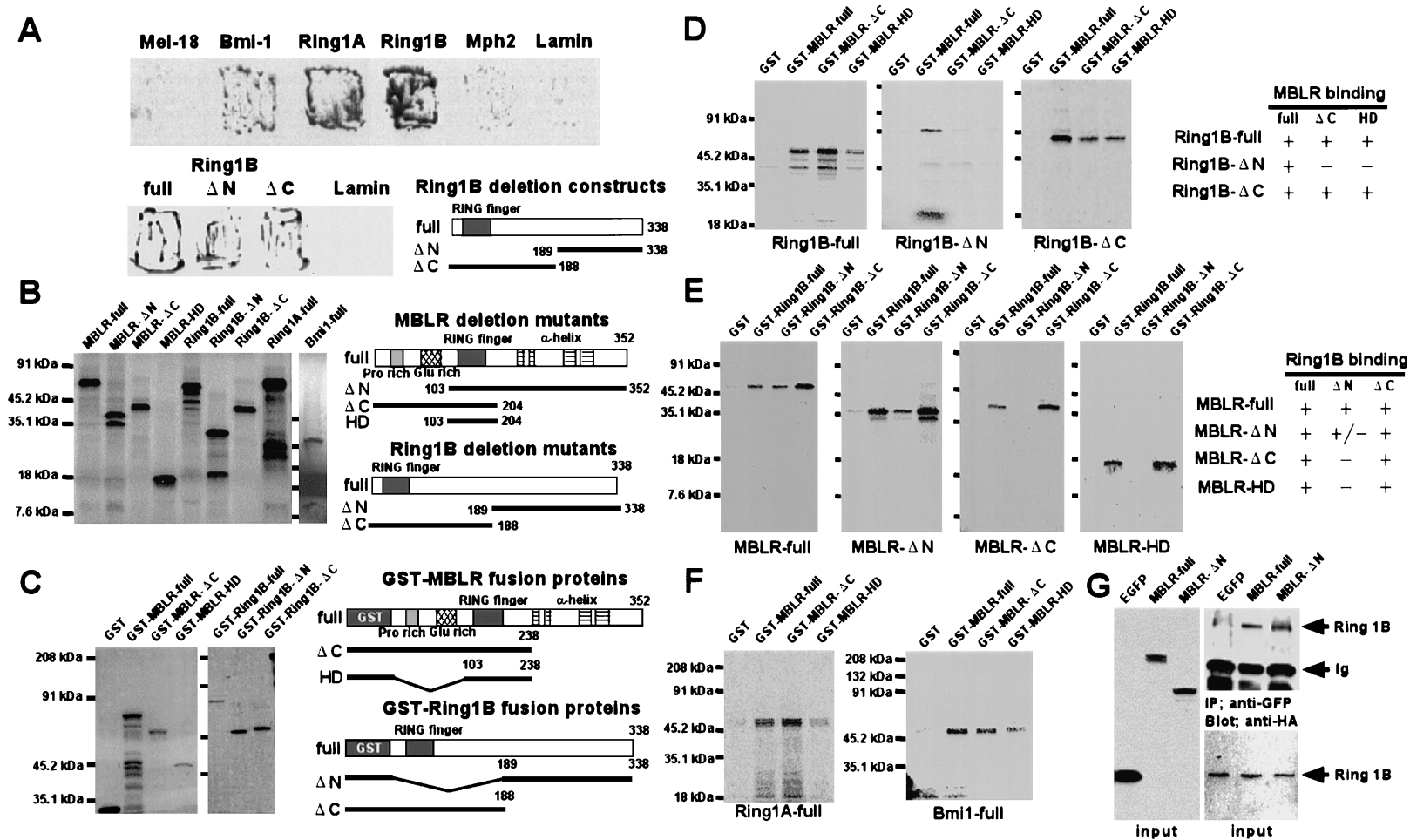

Figure 3 MBLR interacts with Ring1B via its highly homologous domain (HD). (A) Interaction of MBLR with PcG proteins detected by yeast two-hybrid assay. MBLR was expressed as a GAL4AD fusion protein and Mel18, Bmi1, Ring1A, Ring1B and Mph2 were expressed as LexADBD fusion proteins in yeast. Transformants were lysed and incubated on media containing X-gal.The relative strength of the interaction was determined by a visual inspection of the $\beta$-galactosidase assay. LexADBD-Lamin fusion protein was used as a negative control. A schematic representation of the Ring1B deletion constructs is shown on the lower right. (B) In vitro transcription translation products used for GST pull-down assay. The full-length and the indicated truncated proteins were synthesized in vitro, separated by SDS-PAGE and visualized by a BAS-2000II Bio-Imaging Analyser. Sizes of molecular weight markers are indicated in the left. A schematic representation of the constructs used in the in vitro transcription translation is shown on the right, and amino acids are numbered in the various truncated proteins. (C) GST-fusion proteins used for GST pull-down assay. The full-length and the indicated truncated proteins were bacterially produced, and then immobilized on GSH-sepharose beads. After being washed, the bound proteins were separated by $10 \%$ SDS-PAGE and stained with Coomassie Brilliant Blue. Sizes of the molecular weight markers are indicated in the left. A schematic representation of the GST-fusion proteins is shown on the right, and amino acids are numbered in the various truncated proteins. (D) The full-length and indicated truncated Ring1B proteins were incubated with GST, GST-MBLR-full, GST-MBLR- $\Delta$ C, or GST-MBLR-HD immobilized on GSH-sepharose beads. After washing, the bound proteins were separated by SDS-PAGE and visualized by a BAS-2000II Bio-Imaging Analyser. Sizes of molecular weight markers are indicated on the left. A summary of the binding data is shown on the right. The interaction between each Ring1B protein and GST-fusion protein is designated by + , and - indicates no interaction. (E) The full-length and indicated truncated MBLR proteins were incubated with GST, GST-Ring1B-full, GST- Ring1B$\Delta \mathrm{N}$, or GST- Ring1B- $\Delta \mathrm{C}$ immobilized on GSH-sepharose beads. After washing, the bound proteins were separated by SDS-PAGE and visualized by a BAS-2000II Bio-Imaging Analyser. Sizes of molecular weight markers are indicated on the left. A summary of the binding data is shown on the right. The interaction between each MBLR protein and GST-fusion protein is designated by + , while $+/-$ indicates a weak interaction, and -indicates no interaction. (F) The full-length Ring1A and Bmi1 proteins were incubated with GST, GSTMBLR-full, GST-MBLR- $\Delta$ C, or GST-MBLR-HD immobilized on GSH-sepharose beads. After washing, the bound proteins were separated by SDS-PAGE and visualized by a BAS-2000II Bio-Imaging Analyser. Sizes of molecular weight markers are indicated on the left. (G) Immunoprecipitation of HEK293 cells transiently co-transfected with MBLR and Ring1B expression plasmids. At $48 \mathrm{~h}$ after transfection of EGFP-MBLR and HA-tagged-Ring1B expression plasmids, cells were lysed and immunoprecipitated in the presence of anti-EGFP antibody. After elution by boiling, samples were analysed by $10 \%$ SDS-PAGE and Western blot with anti-HA antibody. Aliquots of the lysates were analysed by Western blot with anti-EGFP and anti-HA antibodies (input). 
GST-hMBLR, but that no interaction occurred with GST alone (Fig. 3D,E).

Next we determined the precise binding domain for MBLR and Ring1B by using several deletion mutants of respective genes. The deletion constructs of Ring1B containing amino acids $189-338$ and $1-188$ fused to the GAL4DBD (Ring1B- $\Delta \mathrm{N}$ and $\Delta \mathrm{C}$, respectively) interacted with MBLR similarly to full-length Ring1B in a yeast two hybrid assay (Fig. 3A, bottom panel). Further analyses were performed using the in vitro GST pulldown assay. Several deletion mutants of MBLR and Ring1B were synthesized in vitro or expressed as GST fusion proteins (Fig. 3B,C). We found that a truncated Ring1B derivative lacking amino acids 189-338 (Ring1B- $\Delta$ C) was able to bind efficiently not only to an intact MBLR protein fused to GST, but also to deleted variants lacking amino acids 239-352 and 1-102 plus 239-352 (GST-MBLR- $\Delta \mathrm{C}$ and GST-MBLR-HD). A Ring1B derivative lacking amino acids 1-188 (Ring1B$\Delta \mathrm{N}$ ) interacted only with the intact MBLR (Fig. 3D). An amino-terminal-truncated MBLR derivative containing amino acids $103-352$ was able to bind to both GST-Ring1B- $\Delta \mathrm{C}$ and GST-Ring1B- $\Delta \mathrm{N}$. However truncated variants, MBLR proteins lacking amino acids 103-352 (MBLR- $\Delta$ C) or amino acids 1-102 plus 239-352 (MBLR-HD), were unable to interact with the C-terminal half of Ring1B fused to GST (GSTRing1B- $\Delta \mathrm{N}$ ) (Fig. 3E). These results indicate that the direct interaction between MBLR and Ring1B occurs through two regions. One lies in the central homologous region of MBLR and the $\mathrm{N}$-terminal portion of Ring1B containing the RING finger domain, whereas the other spans residues in the C-terminal portion of MBLR and Ring1B. Since the C-terminal region of MBLR encompassing residues 103-352 (MBLR- $\Delta N)$ showed weaker interaction with GST-Ring1B- $\Delta \mathrm{N}$ compared with MBLR-full, the N-terminal region of MBLR may also assist the interaction to some extent.

Finally, we also investigated the interaction between MBLR and other PcG proteins, such as Ring1A and Bmil. Intact ${ }^{35}$ S-labelled Ring1 A and Bmi1 interact with MBLR and with either of its truncated derivatives MBLR- $\triangle \mathrm{C}$ or MBLR-HD (Fig. 3F). Taken together, these results show that MBLR interacts directly with at least a subset of $\mathrm{PcG}$ proteins, and that its smallest interacting domain contains a RING finger domain and adjacent homologous regions.

To confirm this interaction in mammalian cells, we co-expressed MBLR and Ring1B in HEK293 cells. MBLR and Ring1B were tagged with EGFP and HA epitope, respectively, at their $\mathrm{NH}_{2}$-termini. When the lysate co-expressing EGFP-MBLR and HA-Ring1B was immunoprecipitated with the anti-GFP antibody, HARing1B was detected in the EGFP-MBLR immune complex (Fig. 3G, right upper panel, lanes MBLR-full and MBLR- $\Delta N$ ). HA-Ring1B was not detected in the control EGFP immune complex (Fig. 3G, right upper panel, lane EGFP). The same result was obtained with the lysates co-expressing Myc-tagged MBLR and HARing1B (data not shown). Interestingly, deletion of amino acids 1-102 of MBLR did not affect the interaction with Ring1B, even in the HEK293 cells.

\section{Immunolocalization of MBLR in U2OS cells}

In the interphasic nucleus of some tissue culture cell lines, like the human U2OS cells, the $\mathrm{PcG}$ proteins such as Ring1A, Ring1B, M33, Mph1, Mph2 and Bmi1 colocalize in specific subnuclear domains, termed $\mathrm{PcG}$ bodies (Alkema et al. 1997a,b; Gunster et al. 1997). To investigate the distribution of hMBLR in U2OS cells, we performed a double-staining with anti-hMBLR antibody, pAbR 0 , and the monoclonal antibody against Ring1B. We found that, in contrast to the nuclear speckled distribution of Ring1B, hMBLR showed a fine-grained pattern distributed uniformly throughout the nucleus (Fig. 4 MBLR). Ring1B protein was excluded from the nucleolus and showed a speckled distribution throughout the nucleoplasm, as shown previously (Fig. 4, Ring1B). The different subnuclear distribution of endogenous hMBLR and Ring1B may suggest a functional difference of hMBLR with regard to the mammalian PcG proteins.

\section{Cell cycle-dependent phosphorylation of MBLR}

The intracellular localization of MBLR corresponded to that of interphase U2OS cells. However, in mitotic cells we noted the hMBLR staining outside of the condensed
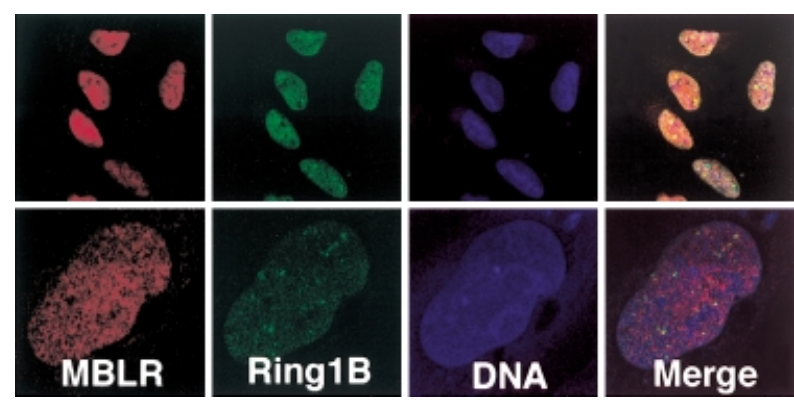

Figure 4 Distribution of endogenous MBLR and Ring1B proteins in normal U2OS cells. Normal U2OS cells were doublestained with anti-MBLR (red) and anti-Ring1B (green) antibodies and analysed by confocal microscopy. TO-PRO-3 iodide (blue, pseudocolour) was used for nuclear counter staining. 
T Akasaka et al.

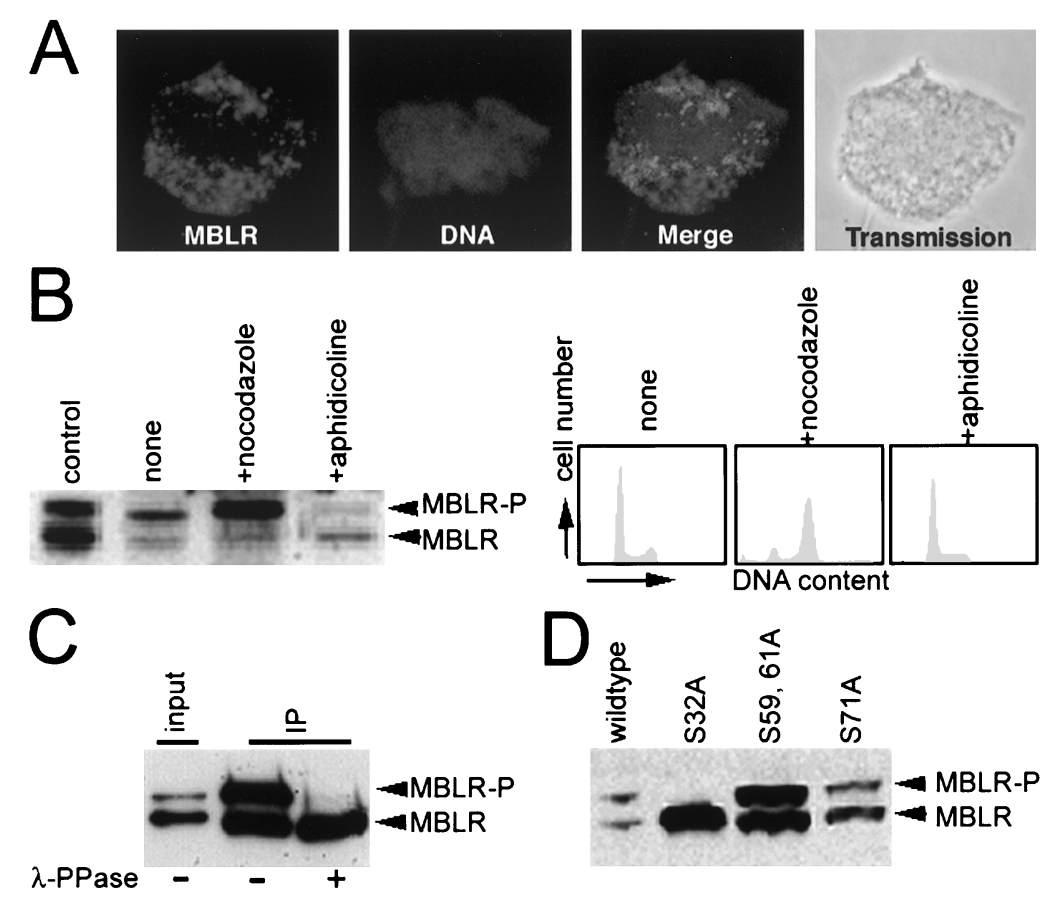

Figure 5 Cell cycle-dependent phosphorylation of MBLR (A). After nocodazole-treatment for synchronization at mitosis, cells were collected and adhered on a glass slide by cytospin preparation. Metaphase U2OS cells were stained with anti-MBLR antibody. Nuclear DNA was stained with TO-PRO-3 iodide. (B) U2OS cells were treated with either nocodazole $(500 \mathrm{~nm} ; 16 \mathrm{~h}) \mathrm{or}$ aphidicoline $(10 \mu \mathrm{g} / \mathrm{mL}$; $20 \mathrm{~h}$ ) and endogenous MBLR was detected by Western blot using anti-MBLR antibody. Lysate from U2OS cells transfected with wild-type hMBLR expression plasmid was loaded as a control. Results of flow cytometric analysis of each sample are indicated at right. (C) HEK293 cells were transfected with Myc-tagged hMBLR expression plasmid. Immunoprecipitated Myc-tagged MBLR was incubated at $30{ }^{\circ} \mathrm{C}$ for $30 \mathrm{~min}$ either in the presence $(+)$ or absence $(-)$ of $400 \mathrm{U}$ of $\lambda$ protein phosphatase (New England Biolabs) and analysed by Western blot using anti-Myc antibody. (D) HEK293 cells were transfected with several mutant Myc-tagged hMBLR expression plasmids and the lysates were analysed by Western blot using anti-Myc antibody.

chromatin (Fig. 5A, MBLR and Merge). We asked whether these changes in cell localization could be due to a post-translational modification of hMBLR at different stages of the cell cycle. U2OS cells were synchronized at G2/M and G1/S by Nocodazole and Aphidicoline, respectively, and analysed by Western blotting with anti-MBLR, pAbR0, antibody. In extracts from cells accumulated at the G2/M boundary we detected an anti-MBLR reactive band that migrated more slowly than the band seen in extracts of nontreated cells. In contrast, extracts from cells accumulated at the G1/S boundary showed almost no slow migrating MBLR band (Fig. 5B). This suggests that MBLR undergoes a cell cycle-regulated post-translational modification.

To investigate whether the alteration of the electrophoretic mobilities of MBLR are related to phosphorylation, we treated immunoprecipitated MBLR with Lambda Protein phosphatase. The treatment eliminated the band shift of MBLR seen on Aphidicoline synchronized cells (Fig. 5C, lane IP+) and indicates that MBLR is post-translationally modified by phosphorylation. Next, we wished to identify which residues were phosphorylated. The observation that MBLR- $\Delta \mathrm{N}$ protein showed only a single migrating band on Western blots (Fig. 3G) suggesting that these residues should be contained within the 102 amino acid residues at the $\mathrm{NH}_{2}{ }^{-}$ terminal end of MBLR. In this domain there are four serine residues at positions 32, 59, 61 and 71. All of them were mutated individually to alanine to examine whether these mutations had any effect on the electrophoretic mobility of MBLR. We found that the substitution of serine 32 abolished the slowly migrating band of MBLR (Fig. 5D, lane S32A), while the mutations of serines 59, 61 and 71 had no effect on the migration of MBLR (Fig. 5D, lanes S59, 61A and S71A). These results indicate that the phosphorylation of serine 32 of MBLR is responsible for the alteration of the electrophoretic mobility of MBLR during mitosis.

To confirm the specific phosphorylation of MBLR during mitosis, we raised an antibody against 
Figure 6 Detection of phosphorylated MBLR by phospho-specific antibody. (A) Cellular lysate of HEK293 cells transfected with wild-type hMBLR expression plasmid was resolved in 10\% SDS-PAGE, followed by immunoblotting with antiMBLR pAbR0 or anti-phospho-MBLR antibody. (B) Normal U2OS cells were stained with anti-phospho-MBLR antibody (green) and nuclei were counterstained with TO-PRO-3 iodide (red). Representative cells in metaphase, anaphase and telophase are shown.

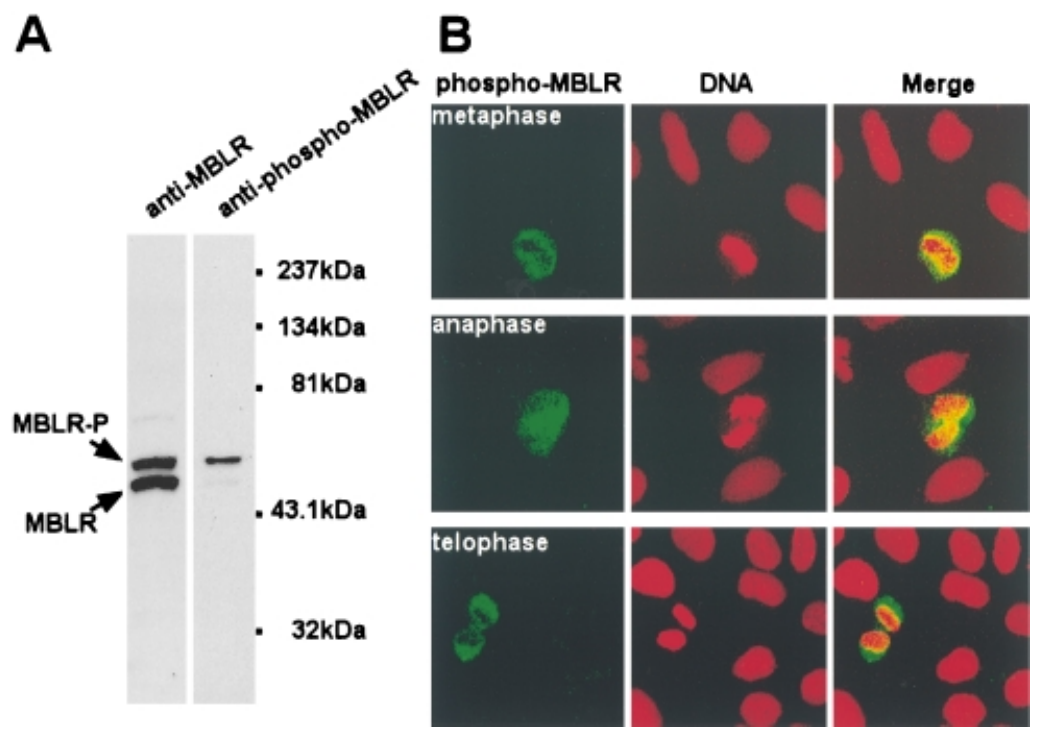

phospho-MBLR peptide. Consistent with the previous characterization, this antibody recognized a single band of $65 \mathrm{kDa}$, which is the molecular mass of phosphorylated MBLR as determined by Western blotting (Fig. 6A). Indirect immunofluorescent studies revealed that the antibody specifically detected phosphorylated MBLR as a diffuse cytoplasmic distribution in the mitotic U2OS cells (Fig. 6B). This diffuse cytoplasmic distribution of phosphorylated MBLR was observed from metaphase to telophase of the mitotic cells. This specific staining pattern was not detected with pre-immune serum (data not shown).

\section{In vitro phosphorylation of MBLR by CDK7}

To confirm the phosphorylation of MBLR, we performed an in vitro kinase assay of GST-MBLR fusion protein using cell nuclear extract. For this assay we used the C-terminal deleted MBLR (amino acids 1-238) because of its better protein stability. GST-MBLR is readily phosphorylated when incubated with the cell nuclear extract (Fig. 7A, lane GST-MBLR), but GST alone is not (Fig. 7A, lane GST). To assess whether the serine 32 residue of MBLR is actually the likely substrate of phosphorylation in this reaction, we analysed the phosphorylated MBLR and S32A mutant MBLR by immunoblot analysis using anti-phospho-MBLR antibody. Only MBLR showed the phosphorylated serine 32 (Fig. 7B, lane 5) when assayed with both nuclear cell extract and ATP.This shows that the serine 32 of MBLR protein is one of the sites phosphorylated by a kinase contained with the nuclear extract. Taken together with the in vivo data (Fig. 4), the serine 32 may be functionally the most important phosphorylation site of MBLR. There are several proline-directed kinases (Pdks) including CDK7, which is known as a component of CAK [cyclin-dependent kinase (CDK)-activating kinase]. CAK has been strongly implicated in cell cycle regulation and the initiation of transcription (Bregman et al. 2000; Kaldis 1999; Nigg 1996). We focused on CDK7, because the phosphorylation site of MBLR had a high similarity to the known substrates for CDK7 (Fig. 7C, S118 of oestrogen receptor $\alpha$ and S77 of retinotic acid receptor $\alpha 1$ ) (Chen et al. 2000; Rochette-Egly et al. 1997). To examine the role of CDK7 in the phosphorylation of MBLR, we performed an in vitro kinase assay using Hela cell nuclear extract from which CDK7 was immunodepleted by anti-CDK7 antibody. We found that in this CDK7-depleted extract phosphorylation of MBLR was significantly reduced to that seen with intact extracts (Fig. 7D, right panel). We also confirmed that there was about a 70\% reduction in the CDK7 content of this nuclear extract by Western blot analysis (Fig. 7D, left panel). These results indicate that, at least in vitro, MBLR is a substrate for CDK7 phosphorylation.

\section{Discussion}

In Drosophila, the presence of over 30 PcG gene loci has been suggested by genetic analyses (Pirrotta 1997a,b; Simon 1995). However, less than half of them have been molecularly or functionally characterized.To understand the function of $\mathrm{PcG}$ complexes, it is necessary to identify other PcG and PcG-related genes. Mel18 and Bmi1 share sequence similarity to Drosophila posterior sex combs (Psc) and its relative $\mathrm{Su}(\mathrm{z}) 2$, and are the most extensively 
T Akasaka et al.

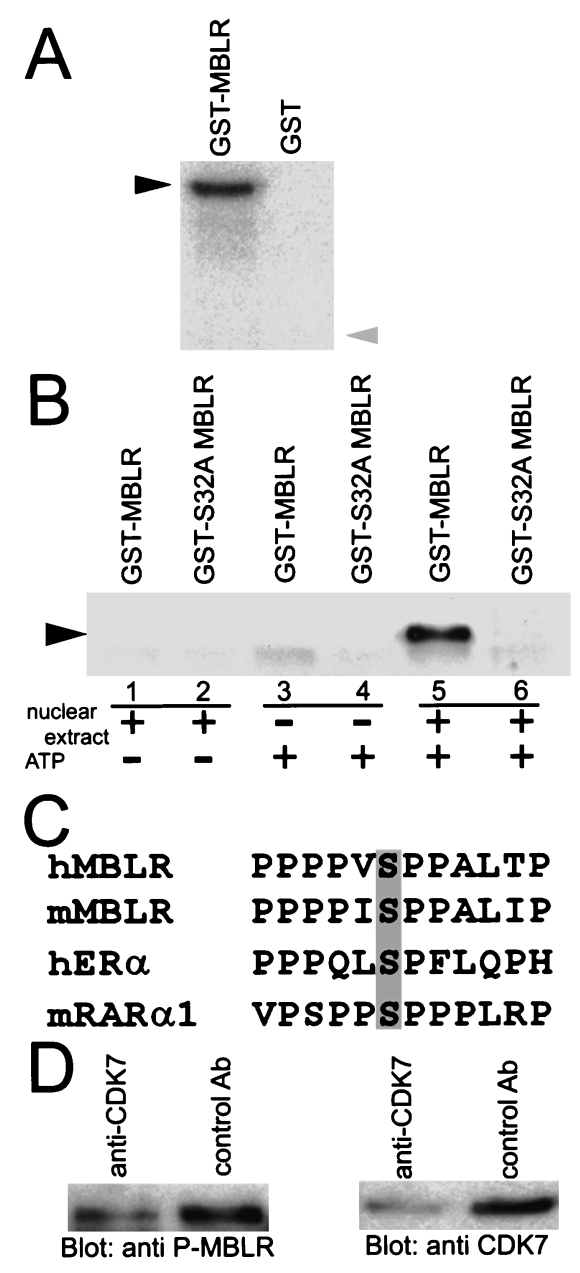

Figure 7 In vitro kinase assay of recombinant GST-MBLR(A) Recombinant GST-MBLR and control GST were incubated with $\left[\gamma-{ }^{32} \mathrm{P}\right]$ ATP in the presence of Hela cell nuclear extract, then precipitated with glutathione-sepharose beads and resolved by $10 \%$ SDS-PAGE. The dried gel was autoradiographed. (B) The serine 32 residue of MBLR is phosphorylated in vitro. Recombinant GST-MBLR and GST-S32A MBLR were incubated separately in the presence of nuclear extract and ATP, and subjected to SDS-PAGE. Analysis of serine 32-phosporylated MBLR was determined by Western blot with anti-phospho MBLR antibody. (C) Comparison of amino acid sequences between the phosphorylation site of hMBLR and other substrates for CDK7. The phosphorylated serine residues are indicated by shading. (D) Effect of CDK7 depletion on in vitro phosphorylation. Recombinant GST-MBLR was incubated with ATP in the presence of CDK7-depleted Hela cell nuclear extract or control extract, immunoprecipitated with glutathionesepharose beads and resolved by 10\% SDS-PAGE. Analysis of serine 32-phosphorylated MBLR was determined as described in (B). analysed mammalian PcG proteins. Screening based on the sequence similarities and molecular interactions with known mammalian PcG proteins allow us to discover new candidates for mammalian PcG proteins. In this study, we have searched the sequence database and identified a potential candidate $P c G$-related gene which has a high similarity to Mel18 and Bmi1, and designated it MBLR (Mel18- and Bmi1-like RING finger protein).

Structural comparison of MBLR with Mel18, Bmi1 and NSPc1 and binding properties to Ring1B suggest that MBLR might be subdivided into at least three distinct sub-regions. The central region (amino acids 125-216) containing a RING finger domain (amino acids 136-174) and adjacent regions are highly homologous to the N-terminal regions of Mel18, Bmi1 and NSPc1 and are essential for binding to Ring1B as well as Mel18 and Bmi1 (Hemenway et al. 1998; Satijn \& Otte 1999). The C-terminal region of MBLR is predicted to form HTH structures similar to the central region of Mel18 and Bmil. However, Mel18 and Bmi1 strongly interact with Mph1 and Mph2 via their HTH regions (Alkema et al. 1997a; Gunster et al. 1997), and MBLR only weakly interacted with Mph2 on a yeast two-hybrid assay. This weak interaction of MBLR with Mph2 might be explained by the structural difference of the putative HTH domain. The most characteristic region for the MBLR protein is the $\mathrm{N}$-terminal region, which contains proline- and glutamic acid-rich domains. A serine 32 residue in a proline-rich domain is demonstrated to be a site of cell cycle-dependent phosphorylation of MBLR. Neither Mel18, Bmi1, nor NSPc1 possesses a homologous region to the $\mathrm{N}$-terminal region of MBLR, while Mel18 and Bmi1 have PEST regions in their C-terminal regions. Bmi1 is also phosphorylated in a cell cycle-dependent manner although its phosphorylation site is not yet determined (Voncken et al. 1999). Since the PEST region of Bmil contains several possible phosphorylation sites, part of the function of the N-terminal region of MBLR might be similar to those of PEST region of Bmi1 and Mel18. It has previously been demonstrated that the accumulation of Bmi1 protein to the subnuclear PcG bodies were mediated by the RING finger and its adjacent domains (Alkema et al. 1997a). Although these domains are extensively conserved between MBLR and Bmi1 and are functionally equivalent as indicated by Ring1B binding, MBLR is not involved in the PcG bodies. Therefore, the $\mathrm{N}$-terminal or C-terminal domains of MBLR might affect the accumulation of MBLR to the PcG bodies. One explanation is that unknown proteins interacting with the $\mathrm{N}$ - or C-terminal region of MBLR would prevent its accumulation to the $\mathrm{PcG}$ bodies. 
Although the involvement of MBLR in the mammalian PRC-1 [Polycomb repressive complex 1 (Shao et al. 1999)]-like complex remains unclear, we suggest that MBLR belongs to the subclass of RING finger proteins represented by mammalian PcG proteins, Mel18 and Bmi1, based on the following observations. First, MBLR functions as a transcriptional repressor like Mel18 and Bmi1. Second, MBLR is able to bind to mammalian PcG proteins (Ring1B, Ring1A and Bmi1) via its central domain, and over-expressed MBLR and Ring1B are co-immunoprecipitated from the lysate of transiently transfected mammalian cells. Third, although MBLR is detected throughout the nucleoplasm in wild-type U2OS cells, over-expression of exogenous MBLR leads to the recruitment of MBLR to PcG bodies in U2OS cells (data not shown). RYBP, a recently identified member of the mammalian PcG complex, is constitutively associated with Ring1A and Ring1B in mouse embryonic extracts, but distributed throughout the nucleoplasm as seen in MBLR (Garcia et al. 1999). Furthermore, a mutant Bmi1 protein lacking the $\mathrm{Zn}$ finger domain induced anterior transformations of the axial skeleton in transgenic mice and displayed a diffuse nuclear localization when expressed in U2OS cells (Alkema et al. 1997a). Thus the formation of PcG bodies should be considered separately from functional aspects of $\mathrm{PcG}$ proteins. Mice lacking the $P c G$ gene show a posterior transformation of the axial skeleton which correlates with an anterior shift of several Hox gene expression boundaries (Akasaka et al. 1996; Core et al. 1997; Takihara et al. 1997; van der Lugt et al. 1994). To ascertain that MBLR is a PcG-related protein, it is necessary to analyse it genetically.We are currently generating MBLR-deficient mice.

In this paper, we clarified that MBLR is a phosphoprotein whose phosphorylation is regulated in a cell cycle-dependent manner. Quite recently, it was reported that Bmi1 is phosphorylated at G2/M and that hyperphosphorylated Bmi1 does not bind to chromatin (Voncken et al. 1999). We did not show that MBLR interacts directly with chromatin. However, MBLR is also phosphorylated during mitosis and dispersed in the cytoplasm. Likewise, some of the trithorax group (trxG) proteins, a protein family which has an opposing effect to $\mathrm{PcG}$ repression, are also phosphorylated in a cell cycledependent manner and excluded from the condensed chromosomes (Muchardt et al. 1996). These lines of evidence suggest that molecules which have a transcriptional memory function may be generally regulated by cell cycle-dependent phosphorylation.

We identified the presence of phosphorylated MBLR outside the condensed chromosome. Since Ring1B dissociates from the condensed chromosome during the mitotic phase (unpublished data), MBLR and Ring1B may interact mainly in the cytoplasm of mitotic cells. Although it is tempting to speculate that such an interaction is the molecular basis for the 'cellular memory' of transcriptional states, neither the exact role of MBLR nor the effect of the interaction of MBLR with Ring1B is understood. Nevertheless, the identification of MBLR-phosphorylation in vivo provides insight for further functional analyses.

Cyclin-dependent kinase 7 (CDK7) was first identified as the catalytic subunit of a complex able to phosphorylate and thereby activate several cell cycleregulatory CDKs (cyclin-dependent kinases) (Fesquet et al. 1993; Poon et al. 1993; Solomon et al. 1993). Later it was also identified as a component of TFIIH, required for basal transcription by RNA polymerase II (Roy et al. 1994). In addition to the T loop of CDKs and the carboxyl-terminal domain (CTD) of the large subunit of RNA polymerase II, several other phosphorylated targets including $\mathrm{p} 53, \mathrm{hER} \alpha$ and $\mathrm{mRAR} \alpha 1$ have been reported (Chen et al. 2000; Ko et al. 1997; RochetteEgly et al. 1997). The similarity in phosphorylation sites between MBLR and hER $\alpha$ and mRAR $\alpha 1$ prompted us to investigate whether CDK7 is involved in MBLR phosphorylation. We performed an in vitro kinase assay and obtained results that support CDK7-mediated MBLR phosphorylation. We did not demonstrate a direct interaction between MBLR and CDK7, but we hypothesize that CDK7 modulates the transcriptional repressor activity of the $\mathrm{PcG}$ complex following the dissociation of a part of the PcG complex through the interaction of phosphorylated MBLR and Ring1B (and perhaps other components of PcG complex).

We have shown that MBLR, which interacts with Ring1B, is phosphorylated during mitosis. In addition, we showed here that MBLR is a potential substrate for CDK7, one of the components of the basal transcriptional machinery. Although our findings indicate a potential link between the basal transcriptional machinery and the PcG complex, to determine any further involvement of $\mathrm{CDK} 7$ in the regulation of $\mathrm{PcG}$ complex it is necessary to clarify a functional role of the MBLRphosphorylation.

\section{Experimental procedures}

\section{Cloning of human and mouse MBLR genes and construction of expression plasmids}

The sequence information of Hunt (Human Novel Transcripts) Human Full Length cDNA Database <http://helixwww.hri.co.jp:443/HRIDB/> allowed us to synthesize specific 
primers for ring finger-S (5'-TGTGTCTCTCCCGACCATGG-3'), and ring finger-AS1 (5'-GCAGTCCTGCAGAAGCCTCC- $3^{\prime}$ ). Then, a cDNA clone of human $M B L R$ $(h M B L R)$ was obtained from an adult testis Marathon-Ready cDNA library (Clontech). For amplification of the cDNA containing the full-length open reading frame (ORF), PCR was performed using hMBLR-S (5'-CGACCATGGAGGGGGTCGCGGT-3') and ring finger-AS2 (3'-TGTGCCTCGAGTCTTCAAGTTATCTTCAGAG-5') primers. The sequence information for the mouse EST clones allowed the synthesis of two specific primers for 5'RACE; mouse $5^{\prime}-\mathrm{R} 15^{\prime}$ CAGCAGGCTTGGGGACTTCTAGACCTC- $3^{\prime}$ ), and mouse 5'-R2 (5'-TGGTGGACAACTATGTTGCATTTTGGGC-3'). Then, a $5^{\prime}$-cDNA fragment of mouse $M B L R$ ( $\left.m M B L R\right)$ was obtained by using a mouse brain Marathon-Ready cDNA library (Clontech) according to the manufacturer's instructions. For amplification of the cDNA containing the full-length ORF, PCR was performed using mouse-full-S (5'-TCTCAACTCGCCAGATTTCTG-3') and mouse-full-AS (3'-GGTGCAATGCAGATATGCAG $-5^{\prime}$ ) primers. The PCR fragments were ligated into a pCR2.1-TOPO cloning vector (Invitrogen) and sequenced. The nucleotide sequence was confirmed by sequencing several clones to avoid errors introduced during the PCR reaction. EGFP-tagged hMBLR expression plasmid (pEGFP-hMBLR-full) and Myc-tagged hMBLR expression plasmid (pcDNA3-MychMBLR) were constructed by ligation into the XhoI site of the pFGFP-C3 plasmid (Clontech) and pcDNA3 (Invitrogen), respectively. Several mutant constructs of pcDNA3-Myc-hMBLR were generated using the GeneEditor in vitro site-directed mutagenesis system (Promega). All mutations were verified by DNA sequencing analysis. The HA-tagged mRing1B expression plasmid (pCEP4-mRing1B) was constructed by ligation into the HindIII/ XhoI sites of the pCEP4 plasmid (Invitrogen).

\section{Northern blot analysis}

Northern blots derived from multiple human tissues containing $2 \mu \mathrm{g}$ of poly(A)+ RNA per lane were obtained from Clontech. The membranes were probed with a $1.8 \mathrm{~kb} h M B L R$ cDNA fragment labelled with $\left[\alpha-{ }^{32} \mathrm{P}\right]-\mathrm{dCTP}$ by the random-primed labelling method and hybridized at $68^{\circ} \mathrm{C}$ for $1 \mathrm{~h}$. Subsequently, the membranes were washed once at room temperature $(\mathrm{RT})$ in $2 \times \mathrm{SSC}, 0.05 \%$ sodium dodecyl sulphate (SDS), and twice for $40 \mathrm{~min}$ each in $0.1 \times \mathrm{SSC}, 0.1 \% \mathrm{SDS}$ at $50^{\circ} \mathrm{C}$.

RT-PCR analysis cDNA from various tissue samples was obtained from Clontech. RT-PCR to evaluate the expression profile of $h M B L R$ transcript was carried out using the following set of primers; sense, 5'-GCTAATGAAGGCACGGGACA-3' and anti-sense, $5^{\prime}$-GCAGTCCTGCAGAAGCCTCC- $3^{\prime}$. The PCR was performed for 33 cycles which consisted of denaturation at $95^{\circ} \mathrm{C}$ for $30 \mathrm{~s}$, annealing at $62{ }^{\circ} \mathrm{C}$ for $30 \mathrm{~s}$, and extension at $72{ }^{\circ} \mathrm{C}$ for $30 \mathrm{~s}$. The amplified products were electrophoresed in $2 \%$ agarose gels and visualized by ethidium bromide staining and UV trans-illumination. To ensure the successful completion of cDNA synthesis for each sample, G3PDH cDNA was amplified with the following primers; sense, 5'-TGAAGGTCGGAGTCAACG-
GATTTGGT-3' and anti-sense, 5'-CATGTGGGCCATGAGGTCCACCAC-3', for 25 cycles.

\section{Whole mount in situ hybridization}

Full-length $m M B L R$ cDNA was subcloned into the pBluescript plasmid (Stratagene) and digoxigenin-labelled anti-sense and sense riboprobes were transcribed from linearized plasmid by T3 and T7 RNA polymerase, respectively (Boehringer Mannheim). Whole mount in situ hybridization was performed as described by Wilkinson (Wilkinson \& Nieto 1993) with the modification that maleic acid buffer $(0.5 \mathrm{~m}$ maleic acid, $0.15 \mathrm{M} \mathrm{NaCl}$, $\mathrm{pH}$ 7.5) was used instead of TBST for washing after antibody reaction.

\section{Cell culture, synchronization and transient transfection}

HEK293, U2OS, primary mouse embryonic fibroblasts (Emfis), CHP134, and L cells were cultured in Dulbecco's modified Eagle's minimum essential medium (D-MEM) supplemented with 10\% $(\mathrm{v} / \mathrm{v})$ heat-inactivated foetal bovine serum (FBS) in a humidified $\mathrm{CO}_{2}$ incubator at $37^{\circ} \mathrm{C}$. For transient transfection, HEK293 cells $\left(3 \times 10^{5}\right)$ or U2OS cells $\left(1.5 \times 10^{5}\right)$ were grown on $3.5 \mathrm{~cm}$ diameter tissue culture dishes, and transfected with $1 \mu \mathrm{g}$ of expression plasmids using Lipofectamine (Gibco BRL). At $48 \mathrm{~h}$ after transfection, cells were used for immunoprecipitation or Western blotting. To attain synchronization, U2OS cells were treated with nocodazole (500 nM; $16 \mathrm{~h}$ ) for G2/M arrest, and with aphidicoline $(10 \mu \mathrm{g} / \mathrm{mL} ; 20 \mathrm{~h})$ for $\mathrm{G} 1 / \mathrm{S}$ arrest. DNA contents were determined by flow cytometric analysis using a FACScan (Becton Deckinson) after fixation with $70 \%$ methanol and subsequent staining with propidium iodide (PI).

\section{Antibody preparation}

The full-length ORF of $h M B L R$ cDNA was subcloned into the XhoI site of the pGEX-4T1 bacterial expression vector (Pharmacia).The GST-hMBLR fusion protein was expressed and purified, then polyclonal antibody against hMBLR was generated by subcutaneous immunization of a rabbit with the recombinant protein. Anti-hMBLR antibody was enriched by Protein A-sepharose. Monoclonal anti-Ring1B antibodies were prepared as described (Atsuta et al. 2001). Monoclonal anti-HA antibody 12CA5 and monoclonal anti-Myc antibody 9E10 were obtained from Boehringer Mannheim and Santa Cruz Biotechnology, respectively. Monoclonal anti-CDK7 ascites fluid (MO-1.1) and polyclonal anti-GFP antibody were purchased from Sigma and Clontech, respectively.

\section{Synthesis of phosphorylated MBLR peptide and production of anti-phospho-MBLR antibody}

A hMBLR peptide, derived from MBLR amino acid residues 26 (P) to 37 (T), [CPPPPPVS(PO3)PPALT], was chemically synthesized by a previously described method (Kitagawa et al.1996) and used as 
the antigen. Rabbits were immunized with these phosphopeptides after conjugation with keyhole limpet haemocyanin through the cysteine residues. Polyclonal antibodies were affinity-purified from these antisera by chromatography on Sepharose CL-4b beads coupled with the same phosphopeptide, followed by passage through the beads linked with a corresponding unphosphorylated peptide. The antibodies were screened for activity by using an ELISA test (Kitagawa et al. 1996).

\section{Immunoprecipitation and Western blot analysis}

Cells were lysed on ice for $30 \mathrm{~min}$ with a 1\% NP-40 lysis buffer consisting of 1\% NP-40, $20 \mathrm{~mm}$ Tris- $\mathrm{HCl}$ (pH 8.0), $150 \mathrm{~mm}$ $\mathrm{NaCl}, 1 \mathrm{~mm}$ EDTA, $10 \%$ glycerol, $10 \mu \mathrm{g} / \mathrm{mL}$ leupeptin, $2 \mu \mathrm{g}$ / $\mathrm{mL}$ pepstatin $\mathrm{A}, 10 \mu \mathrm{g} / \mathrm{mL}$ aprotinin, and $200 \mu_{\mathrm{M}}$ PMSF. Lysates were centrifuged at 15000 r.p.m. for $10 \mathrm{~min}$, then aliquots of the supernatant were incubated for $3 \mathrm{~h}$ at $4{ }^{\circ} \mathrm{C}$ with antibodyconjugated protein $A \& G$ agarose beads (Oncogene). After five washes with the $1 \%$ NP-40 lysis buffer, bound proteins were eluted by boiling for $5 \mathrm{~min}$ in $2 \times$ Laemmli sample buffer [ $125 \mathrm{~mm}$ Tris$\mathrm{HCl}$ (pH 6.8), 1 mm EDTA, 4\% SDS, 20\% glycerol, and 0.2\% bromophenol blue]. Whole-tissue extracts were prepared in PBS containing $1 \times$ complete protease inhibitor cocktail (Roche) from 3-month-old C57Bl/6 mice using PowerGen Homogenizer (Fisher Scientific). The amount of protein was assayed by Protein assay kit (Bio-Rad). All samples were resolved by $10 \%$ sodium dodecyl sulphate polyacrylamide gel electrophoresis (SDS-PAGE) and transferred on to an Immune-Blot PVDF membrane (Bio-Rad) for $1 \mathrm{~h}$ at $140 \mathrm{~mA}$. Blots were blocked with TPBS (phosphate buffered saline, $0.05 \%$ Tween 20 ) containing 5\% skim milk for $1 \mathrm{~h}$ at room temperature and then incubated with an appropriate dilution of each antibody 1 : 10000 for anti-MBLR, $1: 500$ for anti-phospho-MBLR, 1: 4000 for anti-GFP, 1: 2000 for anti-HA, and 1:2000 for anti-Myc antibodies) in TPBS for $1 \mathrm{~h}$. After washing, the membranes were incubated with horseradish peroxidase-conjugated anti-mouse IgG or anti-rabbit IgG (Amersham) for $1 \mathrm{~h}$, and specific proteins were detected using an enhanced chemiluminescence system (NEM Life Science Products).

\section{Immunofluorescence microscopy}

Cells growing on glass cover slips were washed twice in PBS or mitotic cells were collected on to the slide glass using Cytospin (Shandon). Then they were fixed in freshly prepared $2 \%$ paraformaldehyde for $15 \mathrm{~min}$ at RT. The cells were washed twice for $3 \mathrm{~min}$ in PBS and permeabilized with PBS containing 0.5\% Triton $\mathrm{X}-100$ for $5 \mathrm{~min}$ at RT.After washing, the cells were blocked with PBS containing $10 \%$ FBS and $0.02 \%$ Triton X-100 for $1 \mathrm{~h}$ at RT, and then incubated with anti-hMBLR or anti-phospho-MBLR antibody for $30 \mathrm{~min}$ in PBS containing $0.02 \%$ TritonX-100 diluted $1: 500$ or $1: 50$, respectively. The cells were reacted with donkey anti-rabbit IgG coupled with FITC (Jackson Immunoresearch Laboratories) or donkey anti-rabbit IgG coupled with Cy3 (Jackson Immunoresearch Laboratories) diluted 1:300 in blocking solution for $1 \mathrm{~h}$ at RT. For nuclear counterstaining, the cells were incubated with TO-PRO-3 iodide (642/661) (Molecular Probes) after staining with the secondary antibody. After being washed five times for $3 \mathrm{~min}$ each in PBS containing $0.02 \%$ TritonX-100, the cells were embedded in Immunon Perma Fluor Aqueous Mounting Medium (Shandon/Lipshaw) and analysed by confocal microscopy (LSM510 Version2-02/Curl Zeiss).

\section{Repression assays}

Full-length $h M B L R$, mouse Mel18 and Bmi1 were subcloned into the $\mathrm{pM}$ (fusion vector of GAL4 DNA-binding domain, Clontech). The luciferase reporter construct, pFR-Luc, contains five GAL4 binding elements upstream of the SV40 promoter (Promega). Expression values were standardized against Renilla reniformis luciferase expression from $\mathrm{pRL}-\mathrm{TK}$ reference plasmid (Promega). L cells were plated the day before transfection at $1.2 \times 10^{5}$ cell per $24-$ well dish. Transfection was performed using Lipofectamine (Gibco BRL), according to the manufacturer's instructions, and cells were harvested $40 \mathrm{~h}$ after transfection. Luciferase activity was measured by the Dual-luciferase reporter assay system (Promega). Luciferase expression values obtained with the reporter plasmid in the presence of empty $\mathrm{pM}$ effector vector were set to 100 arbitrary units, and luciferase activities in cells transfected with hMBLR, Mel18 or Bmi1 were expressed relative to those obtained with the empty GAL4 vector. The reported results represent the mean values of five independent experiments. Reporter plasmid lacking GAL4 binding sites did not give any significant repression upon hMBLR, Mel18 or Bmi1 expression plasmids (unpublished results).

\section{Yeast two-hybrid assay}

The full-length cDNA of $h M B L R$ was cloned in-frame into the pGAD10 (Gal4 activation domain fusion vector, Clontech). The L40 yeast strain (MATa) containing lexA-His3 and lexA-Lac Z reporter was first transformed with pGAD10-hMBLR using the lithium acetate method (Ito et al. 1983). Murine Mel18, Bmi1, Ring1A, Ring $1 B, M p h 2$, truncated Ring $1 B$ and lamin, as a negative control, were cloned into pBTM116 (LexA DNA-binding domain fusion vector, Paul Bartel and Stan Fiels), and transformed into AMR70 (MAT $\alpha$ ). The transformed clones were mated to each other in all possible combinations on YPAD plates to test for physical interactions among the expressed polypeptides. Then Leu $+\operatorname{Trp}+$ diploids were selected on Leu-Trp- plate and assayed for $\beta$-galactosidase activity.The relative strength of the interaction was determined by visual inspection of $\beta$-galactosidase filter assay (Vojtek et al. 1993).

\section{In vitro transcription/translation and GST pull-down assay}

The full-length and deleted cDNAs were subcloned in the pcDNA3 vector (Invitrogen). RNA was synthesized with $500 \mathrm{ng}$ of supercoiled plasmids and translated in the presence of $10 \mu \mathrm{Ci}$ of $\left[{ }^{35} \mathrm{~S}\right]$ methionine (Amersham Pharmacia) using a rabbit reticulocyte lysate (Promega). For the in vitro GST pull-down 
assay, $10 \mu \mathrm{L}$ of GST-sepharose beads (Amersham Pharmacia) preconjugated with $10 \mu \mathrm{g}$ of either GST alone or several GST-fusion proteins were incubated with $1-3 \mu \mathrm{L}$ of the in vitro translation mixtures for $1 \mathrm{~h}$ at $4{ }^{\circ} \mathrm{C}$ in $200 \mu \mathrm{L}$ of a $0.1 \% \mathrm{NP}-40$ buffer consisting of $0.1 \% \mathrm{NP}-40,20 \mathrm{~mm}$ Tris- $\mathrm{HCl}$ ( $\mathrm{pH} 8.0), 150 \mathrm{~mm} \mathrm{NaCl}$, $1 \mathrm{~mm}$ EDTA, $10 \%$ glycerol, $10 \mu \mathrm{g} / \mathrm{mL}$ leupeptin, $2 \mu \mathrm{g} / \mathrm{mL}$ pepstatin $\mathrm{A}, 10 \mu \mathrm{g} / \mathrm{mL}$ aprotinin, and $200 \mu_{\mathrm{M}}$ PMSF.The beads were washed three times with $1 \mathrm{~mL}$ of the same buffer, then bound proteins were eluted by boiling for 5 min in $15 \mu \mathrm{L}$ of $2 \times$ Laemmli sample buffer. Samples were resolved by $10 \%$ or $15 \%$ SDS-PAGE and dried gels were analysed using a BAS-2000II Bio-Imaging Analyser (FUJIX).

\section{In vitro kinase assay}

Hela cell nuclear extract was prepared as described by Manley et al. (Manley et al. 1983), and the protein concentration was determined as $3 \mu \mathrm{g} / \mu \mathrm{L}$. GST-hMBLR (amino acid 1-238) and GSTMBLR S32A (amino acid 1-238) were expressed and purified from E. coli $\mathrm{DH} 5 \alpha$ using Glutathione Sepharose 4 Fast Flow (Amersham Pharmacia Biotech) and used as substrate $(10 \mu \mathrm{g})$ in a reaction of $6 \mu \mathrm{g}$ of Hela cell nuclear extract, $20 \mathrm{~mm}$ HEPES ( $\mathrm{pH}$ 7.6), $10 \mathrm{~mm} \mathrm{MgCl}$, and $10 \mu \mathrm{Ci}$ of $\left[\gamma^{-32} \mathrm{P}\right]$ ATP.The reaction was allowed to proceed for $30 \mathrm{~min}$ at $30^{\circ} \mathrm{C}$, then the beads were washed three times with washing buffer $25 \mathrm{~mm}$ HEPES ( $\mathrm{pH}$ 7.6),

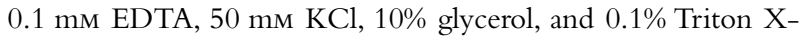
$100]$. The proteins were separated by SDS-PAGE. For the immunodepletion assay, $6 \mu \mathrm{g}$ of MO-1.1 (Sigma) or $6 \mu \mathrm{g}$ of control antibody (anti-CD31: Pharmingen) was pre-bound with $20 \mu \mathrm{L}$ (50\% slurry) of Protein G Sepharose 4 Fast Flow (Amersham Pharmacia Biotech) for $1 \mathrm{~h}$ at $4{ }^{\circ} \mathrm{C}$. The beads were extensively washed in PBS containing $0.1 \%$ Triton X-100 and incubated with $20 \mu \mathrm{L}$ of nuclear extract for $1 \mathrm{~h}$ at $4{ }^{\circ} \mathrm{C}$. After centrifugation, $5 \mu \mathrm{L}$ of the supernatant was used for kinase assay, the same as above, except that $100 \mathrm{~mm}$ ATP was used instead of $\left[\gamma^{3}{ }^{32} \mathrm{P}\right]$ ATP. Each reaction mixture was immediately chilled on ice and extensively washed. Then the glutathione-sepharose beads were boiled in $30 \mu \mathrm{L}$ of $2 \times$ Laemmli sample buffer to elute the GST fusion proteins.

\section{Accession numbers}

The human MBLR (accession no. AB47006) and the mouse MBLR (accession no. AB47007) cDNA sequences have been deposited in the DDBJ/EMBL/GENBANK database.

\section{Acknowledgements}

We are grateful to DrY.Taya (National Cancer Research Institute in Japan), Dr M.Vidal (Developmental and Cell Biology, Centro de Investigaciones Biologicas), Dr T. Nakayama (Department of Molecular Immunology, Chiba University) Dr R.J. Wessells and Krista Golden (Department of Cellular, Molecular and Developmental Biology, University of Michigan) for helpful discussion and critical reading of the manuscript. We thank Dr M.Vidal for providing the Ring1B expression plasmids. We also thank to Dr S. Matsumoto for assistance with the Northern blot and for helpful suggestions and Dr H.T. Yudate for editing the manuscript. This project was in part supported by grants from the Ministry of Education, Culture, Sports, Science and Culture of Japan.

\section{References}

Akasaka, T., Kanno, M., Balling, R., Mieza, M.A., Taniguchi, M. \& Koseki, H. (1996) A role for mel-18, a Polycomb grouprelated vertebrate gene, during the anteroposterior specification of the axial skeleton. Development 122, 1513-1522.

Akasaka, T., Tsuji, K., Kawahira, H., et al. (1997) The role of mel-18, a mammalian Polycomb group gene, during IL-7dependent proliferation of lymphocyte precursors. Immunity $\mathbf{7}$, 135-146.

Akasaka, T., van Lohuizen, M., van Der Lugt, N., et al. (2001) Mice doubly deficient for the Polycomb Group genes Mel18 and Bmi1 reveal synergy and requirement for maintenance but not initiation of Hox gene expression. Development 128, 1587-1597.

Alkema, M.J., Bronk, M., Verhoeven, E., et al. (1997a) Identification of Bmil-interacting proteins as constituents of a multimeric mammalian polycomb complex. Genes Dev. 11, 226-240.

Alkema, M.J., Jacobs, J., Voncken, J.W., et al. (1997b) MPc2, a new murine homolog of the Drosophila polycomb protein is a member of the mouse polycomb transcriptional repressor complex. J. Mol. Biol. 273, 993-1003.

Atsuta, T., Fujimura, S., Moriya, H., Vidal, M., Akasaka, T. \& Koseki, H. (2001) Production of monoclonal antibodies against mammalian Ring1B proteins. Hybridoma 20, 43-46.

Bienz, M. \& Muller,J. (1995) Transcriptional silencing of homeotic genes in Drosophila. Bioessays 17, 775-784.

Borden, K.L. \& Freemont, P.S. (1996) The RING finger domain: a recent example of a sequence-structure family. Curr. Opin. Struct. Biol. 6, 395-401.

Bregman, D.B., Pestell, R.G. \& Kidd, V.J. (2000) Cell cycle regulation and RNA polymerase II. Front. Biosci. 5, D244D257.

Brunk, B.P., Martin, E.C. \& Adler, P.N. (1991) Drosophila genes Posterior Sex Combs and Suppressor two of zeste encode proteins with homology to the murine bmi-1 oncogene. Nature 353, 351-353.

Bunker, C.A. \& Kingston, R.E. (1994) Transcriptional repression by Drosophila and mammalian Polycomb group proteins in transfected mammalian cells. Mol. Cell. Biol. 14, 1721-1732.

Chen, D., Riedl, T., Washbrook, E., et al. (2000) Activation of estrogen receptor alpha by S118 phosphorylation involves a ligand-dependent interaction with TFIIH and participation of CDK7. Mol. Cell 6, 127-137.

Chou, P.Y. \& Fasman, G.D. (1978) Empirical predictions of protein conformation. Annu. Rev. Biochem. 47, 251-276.

Cohen, K.J., Hanna, J.S., Prescott, J.E. \& Dang, C.V. (1996) Transformation by the Bmi-1 oncoprotein correlates with its subnuclear localization but not its transcriptional suppression activity. Mol. Cell. Biol. 16, 5527-5535.

Core, N., Bel, S., Gaunt, S.J., et al. (1997) Altered cellular proliferation and mesoderm patterning in Polycomb-M33-deficient mice. Development 124, 721-729. 
DeCamillis, M., Cheng, N.S., Pierre, D. \& Brock, H.W. (1992) The polyhomeotic gene of Drosophila encodes a chromatin protein that shares polytene chromosome-binding sites with Polycomb. Genes Dev. 6, 223-232.

Fesquet, D., Labbe, J.C., Derancourt, J., et al. (1993) The MO15 gene encodes the catalytic subunit of a protein kinase that activates cdc2 and other cyclin-dependent kinases (CDKs) through phosphorylation of Thr161 and its homologues. EMBO J. 12, 3111-3121.

Franke, A., DeCamillis, M., Zink, D., Cheng, N., Brock, H.W. \& Paro, R. (1992) Polycomb and polyhomeotic are constituents of a multimeric protein complex in chromatin of Drosophila melanogaster. EMBO J. 11, 2941-2950.

Franke, A., Messmer, S. \& Paro, R. (1995) Mapping functional domains of the polycomb protein of Drosophila melanogaster. Chromosome Res. 3, 351-360.

Freemont, P.S. (1993) The RING finger. A novel protein sequence motif related to the zinc finger. Ann. NY Acad. Sci. 684, 174-192.

Freemont, P.S. (2000) RING for destruction? Curr. Biol. 10, R84-R87.

Garcia, E., Marcos-Gutierrez, C., del Mar. Lorente, M., Moreno, J.C. \& Vidal, M. (1999) RYBP, a new repressor protein that interacts with components of the mammalian Polycomb complex, and with the transcription factor YY1. EMBO J. 18, 3404-3418.

Gunster, M.J., Satijn, D.P., Hamer, K.M., et al. (1997) Identification and characterization of interactions between the vertebrate polycomb-group protein BMI1 and human homologs of polyhomeotic. Mol. Cell. Biol. 17, 2326-2335.

Hemenway, C.S., Halligan, B.W. \& Levy, L.S. (1998) The Bmi-1 oncoprotein interacts with dinG and MPh2: the role of RING finger domains. Oncogene 16, 2541-2547.

Irminger-Finger, I. \& Nothiger, R. (1995) The Drosophila melanogaster gene lethal 3,73Ah encodes a ring finger protein homologous to the oncoproteins MEL-18 and BMI-1. Gene 163, 203-208.

Ishida, A., Asano, H., Hasegawa, M., et al. (1993) Cloning and chromosome mapping of the human Mel-18 gene which encodes a DNA-binding protein with a new 'RING-finger' motif. Gene 129, 249-455.

Ito, H., Fukuda, Y., Murata, K. \& Kimura, A. (1983) Transformation of intact yeast cells treated with alkali cations. J. Bacteriol. 153, 163-168.

Jackson, P.K., Eldridge, A.G., Freed, E., et al. (2000) The lore of the RINGs: substrate recognition and catalysis by ubiquitin ligases. Trends Cell Biol. 10, 429-439.

Jacobs, J.J., Kieboom, K., Marino, S., DePinho, R.A. \& van Lohuizen, M. (1999a) The oncogene and Polycomb-group gene bmi-1 regulates cell proliferation and senescence through the ink4a locus. Nature 397, 164-168.

Jacobs, J.J., Scheijen, B., Voncken, J.W., Kieboom, K., Berns, A. \& van Lohuizen, M. (1999b) Bmi-1 collaborates with c-Myc in tumorigenesis by inhibiting c-Myc-induced apoptosis via INK4a/ARF. Genes Dev. 13, 2678-2690.

Joazeiro, C.A. \& Weissman, A.M. (2000) RING finger proteins: mediators of ubiquitin ligase activity. Cell 102, 549-552.
Kaldis, P. (1999) The cdk-activating kinase (CAK): from yeast to mammals. Cell. Mol. Life Sci. 55, 284-296.

Kennison,J.A. (1995) The Polycomb and trithorax group proteins of Drosophila: trans-regulators of homeotic gene function. Annu. Rev. Genet. 29, 289-303.

Kitagawa, M., Higashi, H., Jung, H.K., et al. (1996) The consensus motif for phosphorylation by cyclin D1-Cdk4 is different from that for phosphorylation by cyclin A/E-Cdk2. EMBO J. 15, 7060-7069.

Ko, L.J., Shieh, S.Y., Chen, X., et al. (1997) p53 is phosphorylated by CDK7-cyclin H in a p36MAT1-dependent manner. Mol. Cell. Biol. 17, 7220-7229.

Kyba, M. \& Brock, H.W. (1998) The Drosophila polycomb group protein Psc contacts $\mathrm{ph}$ and Pc through specific conserved domains. Mol. Cell. Biol. 18, 2712-2720.

van Lohuizen, M., Frasch, M., Wientjens, E. \& Berns, A. (1991) Sequence similarity between the mammalian bmi-1 protooncogene and the Drosophila regulatory genes $\mathrm{Psc}$ and $\mathrm{Su}(\mathrm{z}) 2$. Nature 353, 353-355.

van der Lugt, N.M., Alkema, M., Berns, A. \& Deschamps, J. (1996) The Polycomb-group homolog Bmi-1 is a regulator of murine Hox gene expression. Mech. Dev. 58, 153-164.

van der Lugt, N.M., Domen, J., Linders, K., et al. (1994) Posterior transformation, neurological abnormalities, and severe hematopoietic defects in mice with a targeted deletion of the bmi-1 proto-oncogene. Genes Dev. 8, 757-769.

Manley, J.L., Fire, A., Samuels, M. \& Sharp, P.A. (1983) In vitro transcription: whole-cell extract. Meth. Enzymol. 101, 568-582.

Muchardt, C., Reyes, J.C., Bourachot, B., Leguoy, E. \& Yaniv, M. (1996) The hbrm and BRG-1 proteins, components of the human SNF/SWI complex, are phosphorylated and excluded from the condensed chromosomes during mitosis. EMBO J. 15, 3394-3402.

Nigg, E.A. (1996) Cyclin-dependent kinase 7: at the cross-roads of transcription, DNA repair and cell cycle control? Curr. Opin. Cell Biol. 8, 312-317.

Nunes, M., Blanc, I., Maes, J., Fellous, M., Robert, B. \& McElreavey, K. (2001) NSPc1, a novel mammalian Polycomb gene, is expressed in neural crest-derived structures of the peripheral nervous system. Mech. Dev. 102, 219-222.

Orlando, V. \& Paro, R. (1995) Chromatin multiprotein complexes involved in the maintenance of transcription patterns. Curr. Opin. Genet. Dev. 5, 174-179.

Paro, R. (1995) Propagating memory of transcriptional states. Trends Genet. 11, 295-297.

Pirrotta, V. (1997a) Chromatin-silencing mechanisms in Drosophila maintain patterns of gene expression. Trends Genet. 13, 314-318.

Pirrotta, V. (1997b) PcG complexes and chromatin silencing. Curr. Opin. Genet. Dev. 7, 249-258.

Pirrotta, V. (1998) Polycombing the genome: PcG, trxG, and chromatin silencing. Cell 93, 333-336.

Platero, J.S., Sharp, E.J., Adler, P.N. \& Eissenberg, J.C. (1996) In vivo assay for protein-protein interactions using Drosophila chromosomes. Chromosoma 104, 393-404.

Poon, R.Y., Yamashita, K., Adamczewski, J.P., Hunt, T. \& Shuttleworth, J. (1993) The cdc2-related protein p40MO15 is 
T Akasaka et al.

the catalytic subunit of a protein kinase that can activate p33cdk2 and p34cdc2. EMBO J. 12, 3123-3132.

Rastelli, L., Chan, C.S. \& Pirrotta, V. (1993) Related chromosome binding sites for zeste, suppressors of zeste and Polycomb group proteins in Drosophila and their dependence on Enhancer of zeste function. EMBO J. 12, 1513-1522.

Rochette-Egly, C., Adam, S., Rossignol, M., Egly, J.M. \& Chambon, P. (1997) Stimulation of RAR alpha activation function AF-1 through binding to the general transcription factor TFIIH and phosphorylation by CDK7. Cell $\mathbf{9 0 ,}$ 97-107.

Roy, R., Adamczewski, J.P., Seroz, T., et al. (1994) The MO15 cell cycle kinase is associated with the TFIIH transcriptionDNA repair factor. Cell 79, 1093-1101.

Satijn, D.P. \& Otte, A.P. (1999) RING1 interacts with multiple Polycomb-group proteins and displays tumorigenic activity. Mol. Cell. Biol. 19, 57-68.

Schoorlemmer, J., Marcos-Gutierrez, C., Were, F., et al. (1997) Ring1A is a transcriptional repressor that interacts with the Polycomb-M33 protein and is expressed at rhombomere boundaries in the mouse hindbrain. EMBO J. 16, 5930-5942.

Shao, Z., Raible, F., Mollaaghababa, R., et al. (1999) Stabilization of chromatin structure by PRC1, a Polycomb complex. Cell 98, 37-46.

Simon, J. (1995) Locking in stable states of gene expression: transcriptional control during Drosophila development. Curr. Opin. Cell Biol. 7, 376-385.

Solomon, M.J., Harper, J.W. \& Shuttleworth, J. (1993) CAK, the p34cdc2 activating kinase, contains a protein identical or closely related to p40MO15. EMBO J. 12, 3133-3142.

Tagawa, M., Sakamoto, T., Shigemoto, K., et al. (1990) Expression of novel DNA-binding protein with zinc finger structure in various tumor cells. J. Biol. Chem. 265, 20021-20026.

Takihara, Y., Tomotsune, D., Shirai, M., et al. (1997) Targeted disruption of the mouse homologue of the Drosophila polyhomeotic gene leads to altered anteroposterior patterning and neural crest defects. Development 124, 3673-3682.

Vojtek, A.B., Hollenberg, S.M. \& Cooper, J.A. (1993) Mammalian Ras interacts directly with the serine/threonine kinase Raf. Cell 74, 205-214.

Voncken, J.W., Schweizer, D., Aagaard, L., Sattler, L., Jantsch, M.F. \& van Lohuizen, M. (1999) Chromatin association of the Polycomb group protein BMI1 is cell cycle-regulated and correlates with its phosphorylation status. J. Cell Sci. 112, 4627-4639.

Wallrath, L.L. \& Elgin, S.C. (1995) Position effect variegation in Drosophila is associated with an altered chromatin structure. Genes Dev. 9, 1263-1277.

Wilkinson, D.G. \& Nieto, M.A. (1993) Detection of messenger RNA by in situ hybridization to tissue sections and whole mounts. Meth. Enzymol. 225, 361-373.

Wu, C.T. \& Howe, M. (1995) A genetic analysis of the Suppressor 2 of zeste complex of Drosophila melanogaster. Genetics 140, 139-181.

Yudate, H.T., Suwa, M., Irie, R., et al. (2001) HUNT: launch of a full-length cDNA database from the helix research institute. Nucl. Acids Res. 29, 185-188.

Zink, B. \& Paro, R. (1989) In vivo binding pattern of a transregulator of homoeotic genes in Drosophila melanogaster. Nature 337, 468-471.

Received: 24 April 2002

Accepted: 17 May 2002 